\title{
This Scientific Life
}

\author{
Peter C. Doherty
}

B EING ABLE TO SPEND 50+ years dissecting the complexities of infection and immunity has been an immense privilege, especially as such research is increasingly expensive. Those of us who have been lucky enough to find our niche in such a lifestyle should, of course, first thank the taxpayers-in my case of Britain, Australia, and the United States - and the philanthropists and donors who have provided the necessary resources. Then we must also thank all our colleagues who have dedicated their lives to keeping great universities and great research institutes operating at an optimal level.

Success in science is a lot about being in the right place, at the right time, and I have lucked into that optimal situation on several occasions. But ultimately, performance and satisfaction in a research career depend on the people we work with. As we all understand, the penalty of having some early success in biomedical research is that we are out of the laboratory fairly soon. Being a "known name" means that, although we may take a great deal of credit, we are not actually putting in the day-to-day hours at the bench. So, most of all, I would like to thank all who have worked in my various laboratories and put up with me for 3-5 years or more, and for writing about some of that experience. Quite frankly, I have been too terrified to read what you actually wrote but, if I survive COVID-19, I will come to that gradually.

Isn't it great that, although this is a new disease, we have all worked on the basics of infection and immunity and will, just possibly, have made some contribution to illuminating the underlying realities? At the very least, we understand the problem and can think of, and perhaps suggest, useful ways forward. And some of us, in the subsequent paths we have taken, will be directly involved in the actual response to COVID-19, at the laboratory, regulatory or policy level. Society has paid us, and it is terrific if we can pay that back!

So far as I can realistically claim, the strengths that I brought to our joint efforts involved helping to provide financial support and a place to work, suggesting some path that might be followed (some of you quickly identified better directions), providing a forum for open discussion, collaboration, and feedback and helping to write stuff up. A clear personal fault is that rather than forcing you to write (which some already did well), I insisted in putting everything in my own prose and on taking out lots of words. Did you learn usefully from that, or was it just annoying?

Contemporary science is complex and requires multiple skills. Rightly or wrongly, apart from writing, I have thought my own best attribute was to "see something" in data that might not be immediately obvious. As many of you will have learned, one of the advantages of being a laboratory head is that you have a little distance!

Did I actually train anyone? Nobody trained me to do science, although I had occasional help and picked up stuff along the way. My experience of being a junior scientist was "sink or swim," and at least I did not drown. As a mentor, did I do much better than that for any of the great young people that I worked with? What I did try to ensure was that everyone got at least some publication and was credited for the work they did. And I am absolutely clear that any "training" went both ways. I learned at least as much from you as you ever learned from me!

So, I should end this with thanks. The first person to thank is, of course, David Woodland, who hides behind "Woody," but is among the least "lignified" people of anyone I know. I do not know what extreme of desperation caused Woody to organize this volume, but I thank him greatly for taking the trouble. The second is to all of you for being willing to write. Evidently the great Louis Pasteur, toward the end of his life, would look through his published work and murmur (to himself of course): Incroyable! Magnifique! Now, I have the great privilege of being able to get the true story by reading what you wrote, perhaps after a Scotch or two! Thank you for your friendship, for the enthusiasm, for the work that we were able to do together, for being good human beings, and for making the effort, in all sorts of ways!

Address correspondence to: Dr. Peter C. Doherty Department of Microbiology and Immunology The University of Melbourne at the Doherty Institute 792 Elizabeth Street Melbourne Victoria 3000 Australia

E-mail: pcd@unimelb.edu.au; peter.doherty@stjude.org

Department of Microbiology and Immunology, University of Melbourne at the Doherty Institute, Melbourne, Victoria, Australia.

(C) Peter C. Doherty, 2020; Published by Mary Ann Liebert, Inc. This Open Access article is distributed under the terms of the Creative Commons Attribution Noncommercial License (http://creativecommons.org/licenses/by-nc/4.0/) which permits any noncommercial use, distribution, and reproduction in any medium, provided the original author(s) and the source are cited. 